\title{
Change in Temperature Conditions of Slovakia to the Reference Period 1961-2010 and their Expected Changes to Time Horizons Years 2035, 2050, 2075 and 2100 under the Conditions of Changing Climate
}

\author{
Ján Čimo ${ }^{1 *}$, Karol Šinka², Beata Novotná ${ }^{3}$ Andrej Tárník', \\ Elena Aydin', Lucia Toková', Vladimír Kišš' ', Tatijana Kotuš' \\ 1 Department of Biometeorology and Hydrology, Faculty of Horticulture and Landscape Engineering, Slovak \\ University of Agriculture, Hospodárska 7, 94976 Nitra, Slovakia \\ 2 Department of Landscape Planning and Land Consolidation, Faculty of Horticulture and Landscape \\ Engineering, Slovak University of Agriculture, Hospodárska 7, 94976 Nitra, Slovakia \\ ${ }^{3}$ Department of Water Resources and Environmental Engineering, Faculty of Horticulture and Landscape \\ Engineering, Slovak University of Agriculture, Hospodárska 7, 94976 Nitra, Slovakia \\ * Corresponding author's e-mail: jan.cimo@uniag.sk
}

\begin{abstract}
The purpose of the paper was to show cognition from the theory of climate change. The map outputs of these changes offer the climate data from basic elements and characteristics of the energy balance in terms of the current state as well as the trends and assumptions of their future changes in Slovakia. For these agroclimatic analyses, 100 climatic stations in Slovakia spread out to cover all agricultural regions, up to $800 \mathrm{~m}$ above sea level, have been selected. Our analyses are related to the period of years 1961-2010, when measurements and observations were the most homogeneous. The future trends and map outputs of future climate change were determined with the mathematic-statistical methods to the 2035, 2050, 2075- and 2100-year horizons. This study presents the impact of the climate change on the temperature conditions in Slovakia. The temperature changes (average, maximum and minimum temperature) were analysed with forecasts up to year 2100. The forecasts for the 2100-year horizon indicate increasing of the average annual temperature on average by about $2.0^{\circ} \mathrm{C}$, maximum temperature on average by about $2.0^{\circ} \mathrm{C}$ and minimum temperature on average by about $2.5-3^{\circ} \mathrm{C}$ in comparison to the present.
\end{abstract}

Keywords: climate change, average temperature, map outputs, temperature change.

\section{INTRODUCTION}

Temperature is a state variable and is determined by the average kinetic energy value of the disordered motion of molecules of a given substance (air), calculated per one molecule. From a biometeorological point of view, it is one of the plants living conditions, because it determines and influences their basic vital functions. The following temperature characteristics are most commonly used in relation to the living organisms:

- The biological minimum temperature is the minimum temperature at which active vegetation begins in spring or a certain growth phase begins. At this temperature in autumn, the plant stops growing. For most crops, this is approximately $5.0^{\circ} \mathrm{C}$. However, during the vegetation its value differs for different growth phases. They also differ according to the plant type and variety.

- The active temperature is the air temperature that exceeds the biological minimum temperature. It is also referred to as the air temperature, which limits the spread of certain species of plants on the Earth.

- The effective temperature is the air temperature reduced by the biological minimum value. 
- The critical temperature is the extreme temperature (maximum or minimum) at which plant organs or even whole plants are damaged or destroyed.

- Lethal temperature is fatal temperature at which the whole organism dies.

The average monthly and annual air temperatures $(\mathrm{t})$ are determined from time measurements at 7,14 and 21 local time according to the relation:

$$
t=\frac{t_{7}+t_{14}+t_{21}+t_{21}}{4}
$$

where: $t_{7}, t_{14}, t_{21}$ are the temperatures measured at the appropriate observation times.

The temperatures determined by means of this relationship are the closest to the true air temperature average. These characteristics are the most effective from the biological point of view and therefore the most commonly used from the climatic and bioclimatic or physiological viewpoint. The cultural plants life is possible only in a certain temperature range, the upper and lower limits of which, so-called "critical temperatures" are given by the anatomical structure of the plant body and by the physiological processes in their organs. The temperature range over which the plants can develop and grow well varies and depends on the plant species and the areas in which they grow and from which they originate, as it was proven in the studies [Rendeková et al., 2019; Pozníková et al., 2018; Li et al., 2017]. Among the extremes, there is so-called "the optimum temperature band" that best meets the requirements of the plant organism at a given development stage. Generally for the most crops, the optimum can be generally considered to be $15.0-30.0^{\circ} \mathrm{C}$.

\section{MATERIAL AND METHODS}

\section{Study area}

The temperature conditions are one of the basic factors of the complex assessment of the territory. In the landscape, air temperature is the most influenced by geographical location, i.e. latitude determining insolation conditions, altitude, but also orographic conditions, continental or maritimity indicating distance from the sea and others. The temperature conditions of Slovakia are characterized by the exceptional diversity caused mainly by of the territory orographic division (Fig. 1). Mountain chains such as Carpathians, Beskydy, High and Low Tatras and others, form the climatic dams, which have a significant impact on the Slovak climate character and hence its temperature regime. Moreover, the overall weather situation regime has a significant influence on the temporal and spatial Slovakia temperatures distribution.

The average annual vertical temperature gradient in Slovakia is $0.61^{\circ} \mathrm{C}$ per $100 \mathrm{~m}$ height. However, in the summer months, its value increases up to $0.76^{\circ} \mathrm{C}$ and in the winter months it

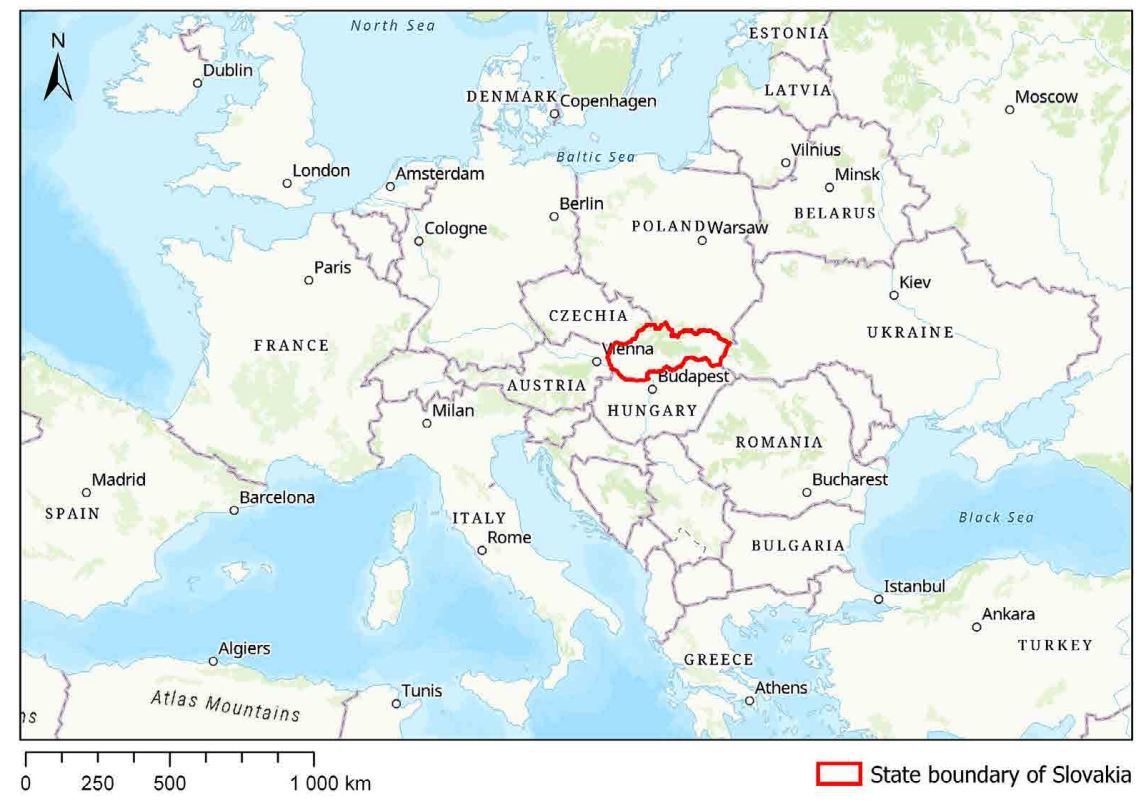

Figure 1. Map of Europe and location of Slovakia 
decreases to $0.33^{\circ} \mathrm{C}$. Extreme temperatures can rank among the characteristics limiting the production process of field and garden crops, and thus often the agricultural production. In Slovakia, the absolute temperature maximum was measured on 20.7.2017 in Hurbanovo: $40.3^{\circ} \mathrm{C}$ and the absolute temperature minimum on 11.2.1929 in Vígl'aš-Pstruša: $41.0^{\circ} \mathrm{C}$.

The basic criterion for the temperature conditions assessment of a site or area is the average annual temperature and in relation to vegetation, the average temperature of the growing season.

In the context of the climate change, a gradual change of the energy balance occurs globally, but above all locally; thus, the temperature regime assessment is justified [ZiernickaWojtaszek 2019]. The climatic data from the meteorological network of stations in Slovakia were provided by the Slovak Hydrometeorological Institute in Bratislava, and used to process the topic. The average, minimum and maximum temperatures values were analysed after years and decades for the period of years of 19612015. Using the mathematical statistical methods, the development trend equations for each weather station were processed separately. The individual functions served as a basis for calculating the temperature changes trend for the years 2035, 2050, 2075 and 2100. The resulting values formed the input data for the map outputs creation in the GIS environment.

\section{Methodology of map output creation in GIS}

ArcGIS software was used to create and process the map outputs-ESRI's Geographic Information System Building Product. This includes a modular system, based on which it is possible to create the solutions that fulfil the requirements of individual users and workgroups for complex enterprise information systems. It is used in many areas: state administration and self-government, academia sphere, education, science and research, industrial enterprises, forestry and agriculture, utilities management, energy production and distribution, transport, telecommunications, etc.

ArcGIS consists of several product groups, from which ArcGIS Desktop was used during work, providing the applications for collecting, processing, searching and presenting geographic information.

\section{Input data preparation}

The selected meteorological stations of SR defined by the XYZ coordinates were loaded into ArcGIS Desktop and then converted to a point vector model (*.shp) in the S-JTSK S coordinate system. Individual meteorological data (air temperature, etc.) for the selected stations were processed in a table design, allowing their easy import and processing in GIS.

As the solution, subject matter was the spatial distribution of meteorological elements on the agricultural land, and also because of the lower density of stations in mountain areas, the areas of Slovakia with an altitude of up to 800 $m$ were defined as an object of interest, with the help of a digital relief model. The sites located higher were excluded from the calculations and graphical outputs.

\section{Interpolation}

The fact only a portion of the data about the analysed phenomenon is available is common in practice, either because of their demanding collection, high cost, or the overall impossibility of the comprehensive mapping realization. Examples include the relief elevation model (terrain) in the contour lines form, the mineral deposit model based on a certain number of boreholes, but also the climatic model creation using the data from meteorological stations. However, the authors were interested in the values occurring in the places that were not mapped, so the spatial structure of the whole studied phenomenon. Therefore, we the authors tried to realize the spatial estimates of values from more or less irregular (alternatively regular) distributed available (selective) data. The result is usually a spatial distribution map of the studied variable values. All approaches to spatial interpolations have a mathematical basis (apart from hand-contoured maps) and they are based on the distribution geometry of the available data and the knowledge of the studied phenomenon physical principle.

From the interpolation methods available in ArcGIS, the Topo to Raster method was used, based on ANUDEM program, version 4.6.3. The method combines the properties of interpolation techniques of IDW, Spline and Kriging. It is optimised for the computational efficiency of local interpolation methods such as IDW, but without losing the surface traceability to global interpolation methods such as Spline and Kriging. Depending 
on the interpolation type, this is a discrete spline method [Sevruk et al. 2009].

The input files in the interpolation process were meteorological stations (as a point vector) containing the attributes-meteorological data, as well as the vector boundary of the SR due to the interpolation process limitation only within the scope of the state. The raster resolution was chosen at the level of $250 \mathrm{~m}$, this includes taking into consideration the input data density and the interpolation range.

\section{Map reports creation}

Maps, depicting the spatial structure of chosen meteorological elements, were created by the interpolation from data from climatic stations for a total of 9 time periods. Interpolated values were reclassified onto the classes for better visual informative merit.

Using the ArcGIS print view, we added a legend, a North Map, a map scale to the outputs and then exported to the JPG format.

\section{RESULTS AND DISCUSSION}

This chapter analyses the climate change influence on the temperatures course (average temperature $T_{\text {average }}$, maximum temperature $T_{\max }$ and minimum temperature $T_{\min }$ ) to the reference period of the years 1961-2010 and its changes to the time horizons of 2035, 2050, 2075 and 2100.

Temperature, as a basic characteristic of the environment energy component, determines the plants life processes such as photosynthesis, respiration, nutrient uptake, transpiration and others. These are the ones that decide on the organic matter production - the crop. As a result, the temperature ranks among the agro-climatic sources of agricultural and vegetable production within it.

The plants requirements for the agro-climatic environmental factors are expressed numerically by the "agroclimatic indicators." On their basis, the agro-climatic conditions of the landscape are evaluated in a synthetic form in the agro-climatic regionalisation. From the agro-climatic factors complex, it is mainly the average temperature $T_{a v}$ erage, maximum temperature $\mathrm{T}_{\text {max }}$, minimum temperature $\mathrm{T}_{\text {min }}$, but also the sum of the average daily air temperatures over the crop's growing season.

The map outputs (Fig. 2a to Fig. 2e) as well as the analysis of the average annual temperatures of individual weather stations for the years
1961-2010 clearly show that there has been a significant change over the last 30 years, and that is warming. While the average annual temperature values of the individual localities in Slovakia did not change significantly during the years 19611980, in the decade 1981-1990 and 1991-2000 the zone with an average annual temperature of $10.5-11.0^{\circ} \mathrm{C}$ appeared. For the period 2001-2010, another zone with an average annual temperature of $11.0-11.5^{\circ} \mathrm{C}$ was added. The processing and analysis of the period 2011-2020 (measurements in this period have not been completed yet) again shows an increase in the next band with an average annual temperature of $11.5-12.0^{\circ} \mathrm{C}$. As mentioned in chapter "Material and methods," from the analysis of the individual meteorological stations, the development trend equations for each meteorological station were processed separately using the mathematical-statistical methods, and these data served as a basis for the prognosis of the isothermal stratification of Slovakia to time horizons 2035, 2050, 2075 and 2100. On the basis of these prognoses, the average temperature map outputs were processed (Fig. $2 \mathrm{f}$ to Fig. 2i), which clearly point to a likely warming trend. From the individual map outputs, it is clear that two temperature zones $\left(11.5-12.0^{\circ} \mathrm{C}\right.$ and $12.0-12.5^{\circ} \mathrm{C}$ ) will be added in the forecast of average temperatures to the year 2035 compared to the previous periods. A temperature zone $\left(12.5-13.0^{\circ} \mathrm{C}\right)$ will be added to 2050, another temperature zone $\left(13.0-13.5^{\circ} \mathrm{C}\right)$ will be added to 2075 and for the 2100 , yet another temperature zone (13.5-14.0 ${ }^{\circ} \mathrm{C}$ ) will appear. The following analysis show that the forecasted average annual temperature will increase by $1.5-2.0^{\circ} \mathrm{C}$ compared to the present.

Looking at the next series of map outputs (Fig. 3a to Fig. 3e) and the analysis of the maximum annual temperatures $\mathrm{T}_{\max }$ of individual meteorological stations for the years 1961-2010 arise again, there has been a significant change over the last 30 years, and that is warming. While the average maximum annual temperature of individual localities of Slovakia did not change significantly over the years 1961-1990, the zone with the average maximum annual temperature of $16.0-16.5^{\circ} \mathrm{C}$ was added in the decade $1991-2000$ and for the period 2001-2010, the zone with an average maximum annual temperature of 16.5$17.0^{\circ} \mathrm{C}$ was contributed. Following the procedure in "Material and methods" from the individual meteorological stations analysis the equations of trend development $T_{\max }$ for each meteorological 

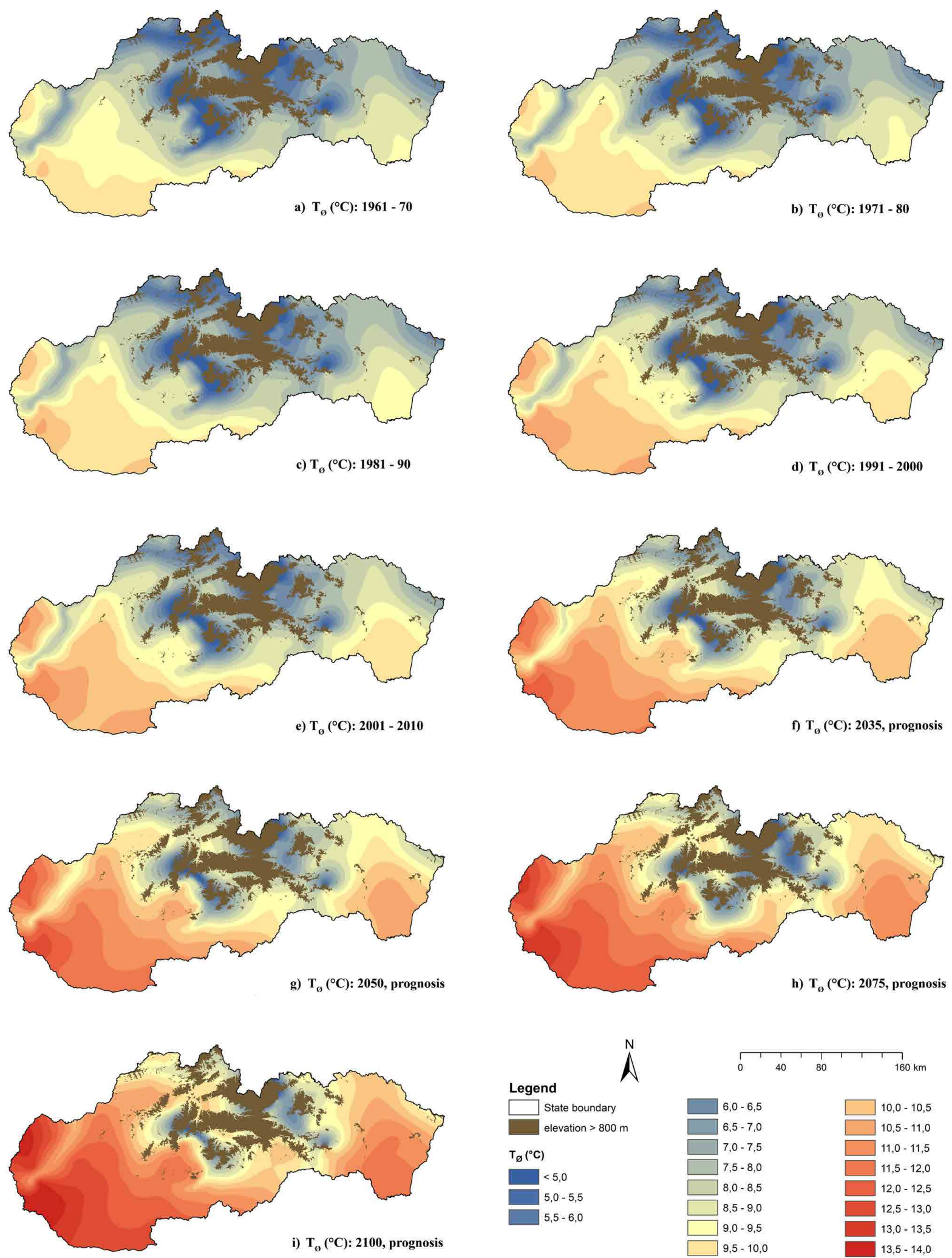

Figure 2. Map of the average annual temperatures in Slovakia (1961-2100)

station were processed by mathematical statistical methods separately, and these data served as a basis for the prognosis of isothermal Slovakia stratification to the time horizons of the years 2035, 2050, 2075 and 2100. From the processed forecasts results, the map outputs of the mean temperatures of maximum temperatures $\mathrm{T}_{\max }$ (Fig. 3f to Fig. 3i) were created; those clearly indicate the probable trend of warming. From the individual map outputs, it is evident that in the 

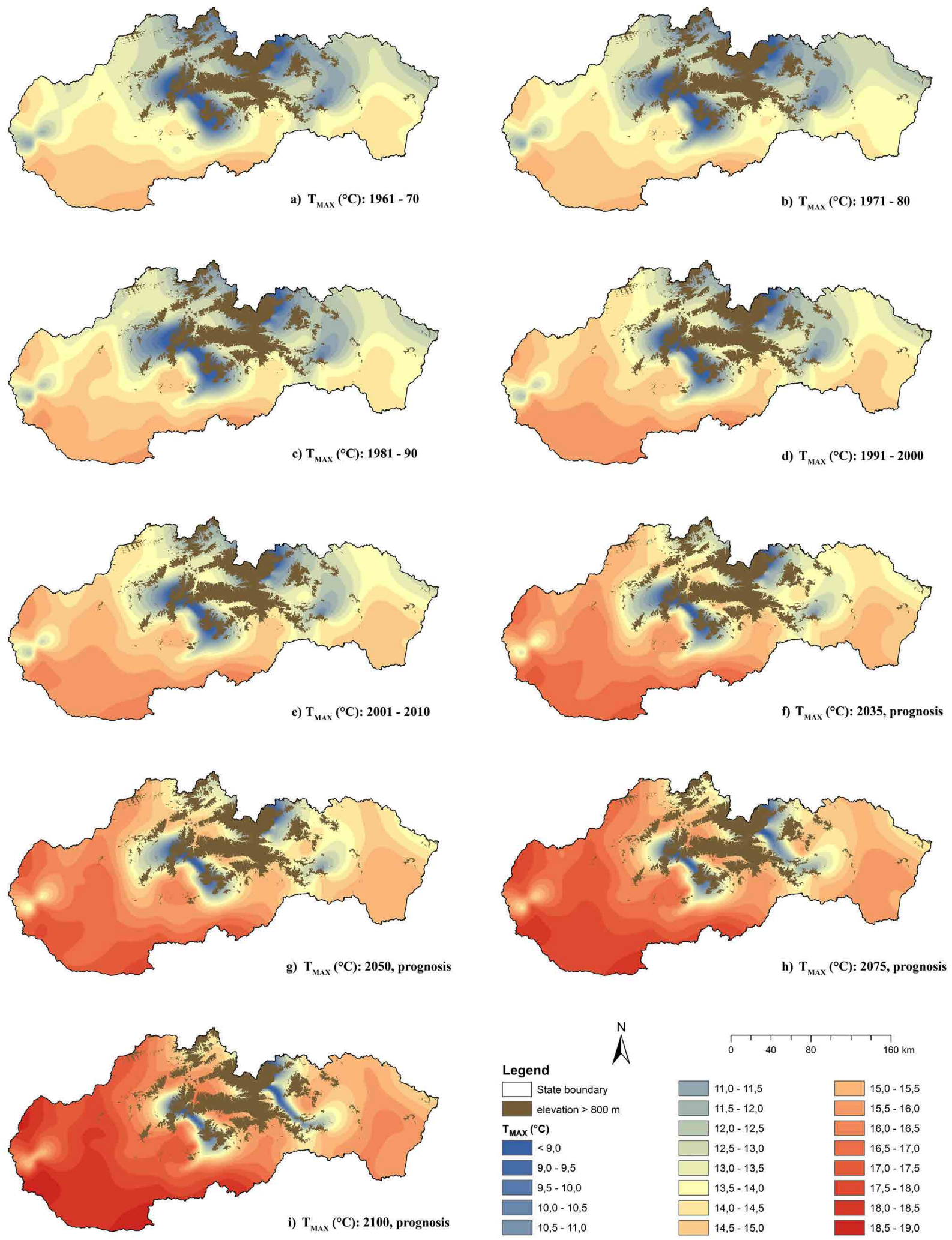

Figure 3. Map of the maximum annual temperatures in Slovakia (1961-2100)

forecast of the development of the average maximum temperatures $\mathrm{T}_{\max }$ to the year $2035 \mathrm{com}$ pared to previous periods, the temperature zone $\left(17.0-17.5^{\circ} \mathrm{C}\right)$ will be added. Another temperature zone $\left(17.5-18.0^{\circ} \mathrm{C}\right)$ will occur for 2050 , an additional temperature zone $\left(18.0-18.5^{\circ} \mathrm{C}\right)$ will be added for 2075 and yet another temperature zone $\left(19.5-19.0^{\circ} \mathrm{C}\right)$ will occur for 2100 . The mentioned analysis showed that the forecast average maximum annual temperature will increase 

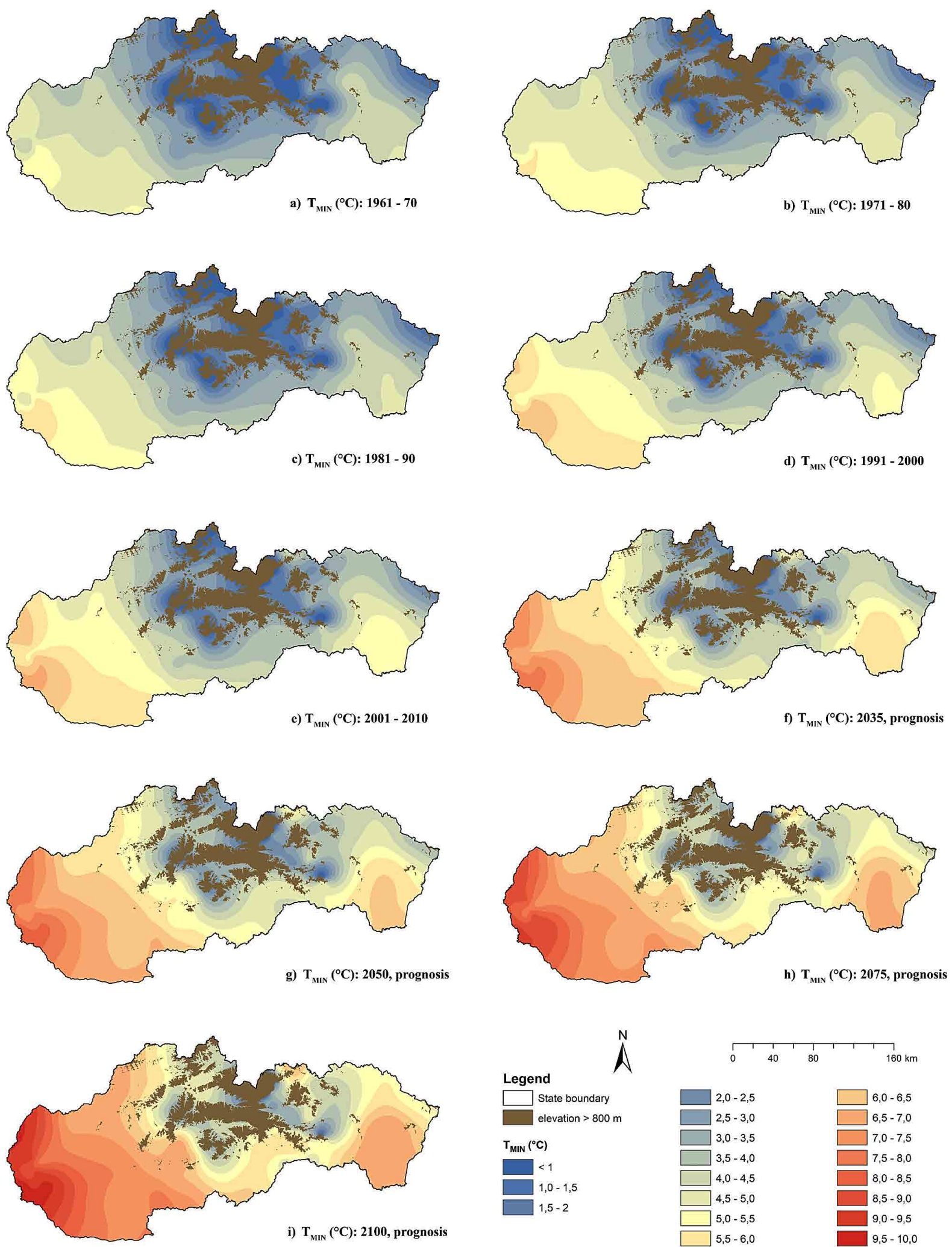

Figure 4. Map of the minimum annual temperatures in Slovakia (1961-2100)

about $2.0^{\circ} \mathrm{C}$ compared to that present in the Danube Lowland.

From the average $\mathrm{T}_{\min }$ values analyses for the decades of 1961-2010 (Fig. 4a to Fig. 4i), we can conclude that warming occurred over the past
30 years there. The decade of 1961-1970 was the coldest in terms of minimum temperatures. In the hottest regions of Slovakia, the average value of $\mathrm{T}_{\min }$ in this decade was $5.0-5.5^{\circ} \mathrm{C}$. The period of the years 1971-1990 did not show any 
significant change either. During this period of two decades, the average value of $\mathrm{T}_{\min }$ increased to $5.5-6.0^{\circ} \mathrm{C}$ in the southern areas of western Slovakia. A significant change began to take effect in the period of the years 1991-2010, and mainly in the decade 2001-2010, when the value of the average minimum temperatures increased about two classes and it reached $\mathrm{T}_{\min } 6.5-7.0^{\circ} \mathrm{C}$ in the Danube lowland.

According to the above-mentioned procedure in the chapter "Material and methods" from the individual meteorological stations analysis, the mathematical-statistical methods were used to process the equations development of the trend $\mathrm{T}_{\min }$ for each meteorological station separately, and these data served as a basis for the prognosis of isothermal stratification of Slovakia to the time horizons of the years 2035, 2050, 2075 and 2100. The map outputs of the minimum temperature averages $T_{\text {min }}$ were created from the processed forecast results that clearly point to a likely warming trend. From the individual map outputs, it is apparent that in the development prognosis of the average minimum temperatures $T_{\min }$ to the year 2035 the temperature zones $\left(7.0-7.5^{\circ} \mathrm{C}\right.$ and $\left.7.5-8.0^{\circ} \mathrm{C}\right)$ were added compared to the previous periods. Another temperature zone appeared in 2050 $\left(8.0-8.5^{\circ} \mathrm{C}\right)$, two temperature zones were added for $2075\left(8.5-9.0^{\circ} \mathrm{C}\right.$ and $\left.9.0-9.5^{\circ} \mathrm{C}\right)$ and for 2100 , another temperature zone appeared (9.5$10.0^{\circ} \mathrm{C}$ ). The above-mentioned analysis shows that the forecast average minimum annual temperature will increase by about $2.5-3.0^{\circ} \mathrm{C}$ in the southern part of Slovakia.

The presented results are in accordance with the conclusions of the other studies oriented on the impact of climate change on the temperature relationships change and in conformity with other studies [Wimmerová et al. 2017; ZiernickaWojtaszek and Krużel 2016; Jing-Hui et al. 2016].

According to the most frequently presented climate change scenarios for Slovakia (SRES A2 and SRES B1), they were developed according to the global Canadian model CGCM3.1 to the horizon of the year 2100, the average air temperature value trend is expected to increase by about 2 to $4^{\circ} \mathrm{C}$ [IPCC, 2018] which corresponds to the presented map outputs.

The temperature changes projection for the period 2081-2100 compared to the period 19862005 (IPCC) simulates the changes according to the different anthropogenic impact scenarios.
For the RCP2.6 scenario, it is a temperature increase of about $1{ }^{\circ} \mathrm{C}$, for the RCP4.5 scenario, it is a temperature increase by about $1.8^{\circ} \mathrm{C}$, for the RCP6.0 scenario it is a temperature increase by approximately $2.2^{\circ} \mathrm{C}$, while for the RCP8.5 scenario, the temperature will increase by as much as about $3.7^{\circ} \mathrm{C}$.

\section{CONCLUSIONS}

In conclusion, it can be state that total warming has been recorded during the last 30 years [Omar et al. 2015]. The expected warming will also significantly affect the current regionalisation of agricultural production and the distribution pattern of field and horticultural crops. This will enable shifting of the temperature-intensive crops from the lower regions to the higher regions of Slovakia. The outputs maps could be also source of relevant information for farmers in their specific information systems [Leitmanová et al. 2013].

An agroclimatic analysis showed that in the last 30 years there has been an earlier onset of the positive temperatures in the spring, which causes more intense melting of the snow cover and a growing trend of floods, especially during the spring period, as it shown in the study [Rukundo and Dogan 2016].

In conclusion, it can be stated that there has been an increase in average temperatures for the years 1961-2010. The greatest increase in average temperatures was recorded for the period of 1981-2010, for maximum temperatures it was 1991-2010 and for minimum temperatures it was 1971-2010. The presented prognoses to the time horizon of the year 2100 show that the forecast average annual temperature will increase on average by about $2.0^{\circ} \mathrm{C}$, the maximum temperature will increase on average by about $2.0^{\circ} \mathrm{C}$ and the minimum temperature will increase on average by about $2.5-3.0^{\circ} \mathrm{C}$.

\section{Acknowledgements}

This publication is the result of the project implementation: „Scientific support of climate change adaptation in agriculture and mitigation of soil degradation" (ITMS2014 + 313011W580) supported by the Integrated Infrastructure Operational Programme funded by the ERDF; and it was supported also by grants VEGA 1/0747/20, KEGA 026SPU-4/2020 and GA SPU 03-GASPU-2018. 


\section{REFERENCES}

1. IPCC, Summary for Policymakers, 2018, https:// www.ipcc.ch/site/assets/uploads/2018/02/ipcc_ wg3_ar5_summary-for-policymakers.pdf.

2. Jing-Hui M. et al. 2016. Analysis of the Temporal and Spatial Distribution of Haze and its Influencing Factors in Shanghai. Polish Journal of Environmental Studies, 25(5), 1965-1974, doi: 10.15244/pjoes/62128.

3. Leitmanova M. et al. 2013. Concept of Information System for Land Consolidation Projects. Acta Horticulturae et Regiotecturae, 16(2), 40-43, doi. org/10.2478/ahr-2013-0010.

4. Li S. et al. 2017. Analysis of the Spatiotemporal Land-Use/Land-Cover Change and its Driving Forces in Fuxian Lake Watershed, 1974 to 2014. Polish Journal of Environmental Studies, 26(2), 671-681. doi: 10.15244/pjoes/65737.

5. Omar O.L. et al. 2015. Hydroclimatic Trends in Areas with High Agricultural Productivity in Northern Mexico. Polish Journal of Environmental Studies, 24(3), 1165-1180, doi: 10.15244/pjoes/31221.

6. Pozníková G. et al. 2018. Quantifying turbulent energy fluxes and evapotranspiration in agricultural field conditions: A comparison of micrometeorological methods. Agricultural Water Management, 209( 30 October), 249-263. https://doi.org/10.1016/j. agwat.2018.07.041.
7. Rendeková A. et al. 2019. Effects of invasive plant species on species diversity: implications on ruderal vegetation in Bratislava City, Slovakia, Central Europe. Acta Societatis Botanicorum Poloniae, 88, 3621 (2019).

8. Rukundo E, Dogan A. 2016. Assessment of Climate and Land Use Change Projections and their Impacts on Flooding. Polish Journal of Environmental Studies, 25(6), 2541-2551, doi: 10.15244/pjoes/63781.

9. Sevruk B., Ondrás M., Chvila B. 2009. The WMO precipitation measurement intercomparisons, Atmos. Res., 92, 3, 376-380. https://doi.org/10.1016/j. atmosres.2009.01.016.

10. Ziernicka-Wojtaszek A, Krużel J., 2016. The Diversification of Air Temperature Trends in Poland (1981-2010). Polish Journal of Environmental Studies, 25(5), 2205-2209, doi: 10.15244/pjoes/62636.

11. Ziernicka-Wojtaszek A., 2019. Pluviothermal Regionalization of Poland in Light of Present-Day Climate Change. Polish Journal of Environmental Studies, doi:10.15244/pjoes/99976.

12. Wimmerová M. et al. 2017. Effect of artificially induced drought on growth and productivity of selected crops within field experiment in Bohemian-Moravian highlands. In MendelNet 2017: Proceedings of International PhD Students Conference. Brno: Mendel University in Brno, 169-173. https://mnet.mendelu. cz/mendelnet2017/mnet_2017_full.pdf. 